\title{
Cytochromes in Streptococcus faecalis var. zymogenes Grown in a Haematin-containing Medium
}

\author{
By T. W. RITCHEY AND H. W. SEELEY, JUN. \\ Laboratory of Microbiology, Cornell University, Ithaca, N.Y. I4850, U.S.A.
}

(Received 25 March 1974; revised 22 July 1974)

\begin{abstract}
SUMMARY
Functional cytochromes were found in the membrane fraction of Streptococcus faecalis var. zymogenes grown aerobically with haematin. Molar growth yields showed that the cytochrome system produced additional ATP. Inhibitors and uncouplers of oxidative phosphorylation verified the presence of cytochromes in the membrane fraction. Spectra indicated both $a$ and $b$ type cytochromes when cultures were grown with haematin. Without haematin, only a flavin system of electron transport developed without additional ATP generation. Bacteria grown anaerobically with haematin did not form cytochromes.
\end{abstract}

\section{INTRODUCTION}

The streptococci traditionally have been considered to be devoid of cytochromes; those species in which pathways to oxygen exist transfer electrons through flavin enzymes. Evidence is increasing, however, to show that certain strains of streptococci form cytochromes under appropriate growth conditions with a concomitant energy advantage.

Whittenbury (1964) reported the presence of bands corresponding to $a_{2}$ and $b$ type cytochromes in Streptococcus faecalis (strain H69D5) when grown in medium supplemented with heated blood. He did not determine whether the cytochromes were functional, vestigial or artifacts resulting from cultural conditions. Bryan-Jones \& Whittenbury (I969) reported the presence of a $b_{2}$ type cytochrome in the membrane fraction of $S$. faecalis (strain $58 \mathrm{I}$ ) when grown in a medium supplemented with haematin. This membrane fraction coupled the oxidation of NADH to the formation of ATP from ADP and inorganic phosphate; however, there was an endogenous ATP production of nearly $65 \%$ due to adenylate kinase. The absorption bands did not appear in bacteria grown in a haematin medium under anaerobic conditions and it was concluded that oxygen was necessary for the appearance of cytochromes. Sijpesteijn (1970) reported that $S$. lactis, grown aerobically in a medium containing haemin, showed spectra of the $a_{2}$ and $b$ types of cytochromes. Most recently, van der Wiel-Korstanje \& de Vries (1973) described a strain of Bifidobacterium, isolated from faeces, which produced either cytochromes $b$ and $a$ or $b$ and $d$ when grown in a medium containing lysed red blood cells.

Gallin \& VanDemark (1964) observed low levels of oxidative phosphorylation in $S$. faecalis (strain IOCI) during the oxidation of NADH by extracts of aerobically grown bacteria. They postulated that phosphorylation may have occurred at the 'NADH-flavin' level, or during the oxidation of naphthoquinone. Later, Smalley, Jahrling \& VanDemark (I968) used molar growth yields as evidence for oxidative phosphorylation with the same organism, and obtained a P:O ratio approximating 0.6. Faust \& VanDemark (1970) used fumarate as an electron acceptor for NADH oxidation in membrane fractions of $S$. faecalis 
(strain IOCr) to demonstrate a $\mathrm{P}: \mathrm{O}$ ratio of $\mathrm{O} \cdot \mathrm{I}$. In contrast to these findings Bryan-Jones \& Whittenbury (I969) were unable to demonstrate oxidative phosphorylation in their strain of $S$. faecalis in the absence of haematin.

After a survey of several species of streptococci, a strain of Streptococcus faecalis var. zymogenes was selected for investigation of cytochromes. The selection was based on the fact that the organism grew vigorously in aerobic culture and on blood agar plates and was haemolytic.

\section{METHODS}

Molar growth yields. Streptococcus faecalis var. zymogenes strain TR was from the culture collection of the Laboratory of Microbiology, Cornell University. The partially defined medium of O'Kane \& Gunsalus (I948) was used with various concentrations of substrates, and included/1: $100 \mathrm{mg}$ cysteine, $0.02 \mathrm{mg}$ lipoic acid and $0.5 \mathrm{~g}$ sodium acetate. Enzymically hydrolysed casein was substituted for acid-hydrolysed casein. The substrates, salts, and vitamins were filter-sterilized and added aseptically prior to inoculation of $50 \mathrm{ml}$ volumes of medium. Haematin (Calbiochem) was added at $20 \mu \mathrm{g} / \mathrm{ml}$ unless otherwise noted. Haematin was prepared monthly by the filter-sterilization of $0.5 \mathrm{~g}$ haematin dissolved in $100 \mathrm{ml}$ $0.2 \mathrm{M}-\mathrm{KOH}$, and was stored at $5{ }^{\circ} \mathrm{C}$. Anaerobic growth was obtained in $50 \mathrm{ml}$ graduated flasks in an anaerobic incubator. The medium was rapidly cooled and inoculated $(0 \cdot 1 \%$ from an $\mathrm{I} 8 \mathrm{~h}$ culture) to avoid redissolving any oxygen. Aerobic growth was accomplished in $250 \mathrm{ml}$ baffled flasks. After I I to I $5 \mathrm{~h}$ of growth at $37^{\circ} \mathrm{C}$ the biomass became constant (determined for each substrate concentration by measurement at $650 \mathrm{~nm}$ with a Beckman DU spectrophotometer) and was immediately harvested. The spent medium was frozen, while the resulting bacterial pellet was washed twice with $35 \mathrm{ml} \mathrm{O} \cdot 0 \mathrm{I} \mathrm{M}$-potassium phosphate buffer $\mathrm{pH} 7 \cdot 2$. The bacteria were dried in pre-heated weighing pans at $100{ }^{\circ} \mathrm{C}$ to a constant weight. Molar growth yields (Y), expressed as $\mathrm{g}$ dry wt/mol substrate, were calculated by the method of Bauchop \& Elsden (1960), who defined the ATP yield as the number of moles of ATP produced per mole of substrate utilized.

Products of substrate fermentation. End-product analysis was carried out on the frozen spent medium with a High Efficiency Gas Chromatograph (Hewlett \& Packard). The columns were packed with Polypack-2, a bead-like material made of ethylvinylbenzene cross-linked with divinylbenzene to form a polymer (not requiring a liquid phase). The carrier gas (helium) was adjusted to a flow rate of $15 \mathrm{ml} / \mathrm{min}$, air at $280 \mathrm{ml} / \mathrm{min}$, and hydrogen at $80 \mathrm{ml} / \mathrm{min}$. The column oven temperature was $130^{\circ} \mathrm{C}$, while the injection portal and the flame detector were at $240^{\circ} \mathrm{C}$. Standards of lactate, pyruvate, formate, acetate, ethanol, acetylmethylcarbinol and 2,3-butanediol were used with a range of 10 and an attenuation of 8 . The spent medium was injected directly into the portal.

Preparation of cell-free extracts. Bacteria were grown in a medium containing $(\mathrm{g} / \mathrm{l})$ : tryptone, I0; yeast extract, 5 ; glucose, $5 ; \mathrm{K}_{2} \mathrm{HPO}_{4}, 2$; at an initial $\mathrm{pH}$ of $7 \cdot 2$. When the $\mathrm{pH}$ reached $6.0\left(1 \%\right.$ inoculum from an $18 \mathrm{~h}$ culture, $37{ }^{\circ} \mathrm{C}$, shaking in baffled flasks for approx. $9 \mathrm{~h}$ ) the growth was harvested at $10000 \mathrm{~g}$ for $\mathrm{I} 5 \mathrm{~min}$ and washed twice in $0.0 \mathrm{I} \mathrm{M}-\mathrm{N}$-trismethyl-2-amino-ethane-sulfonate (TES; Calbiochem) $\mathrm{pH} \mathrm{7.3,} \mathrm{broken} \mathrm{in} \mathrm{an} \mathrm{X-press}$ (Biotech, New York, New York) at $-25{ }^{\circ} \mathrm{C}$ and $20000 \mathrm{lb} / \mathrm{in}^{2}$, then centrifuged at $48000 \mathrm{~g}$ for $25 \mathrm{~min}$. The pellet was washed once in TES buffer, recentrifuged at $48000 \mathrm{~g}$ for $20 \mathrm{~min}$, then resuspended in a few $\mathrm{ml}$ of TES and centrifuged at $3000 \mathrm{~g}$ for Io min. The particulate fraction containing the high molecular weight membrane fraction was saved.

The original supernatant fraction containing the cytoplasm and very small particles (highspeed fraction) was centrifuged at $78000 \mathrm{~g}$ for $90 \mathrm{~min}$ and the resulting supernatant labelled 
'diluted cytoplasm'. The pellet from this sedimentation was washed once in TES buffer and stabilized with 10 \% sucrose. This fraction contained smaller particulate matter.

Measurement of NADH oxidation and coupled phosphorylation. The oxidation of NADH was followed spectrophotometrically at $340 \mathrm{~nm}$ on a Beckman DB-G grating spectrophotometer at $30^{\circ} \mathrm{C}$. Molar quantities of NADH were converted by the extinction at $340 \mathrm{~nm}$ using the molar extinction coefficient of Horecker \& Kornberg (1948). The enzymic assay system to determine NADH oxidation contained: I $5 \mu \mathrm{mol}$ TES buffer; $6 \mu \mathrm{mol} \mathrm{MgCl}_{2}$; $3 \mu \mathrm{mol} \mathrm{KF}$; $\mathrm{I} \cdot 5 \mu \mathrm{mol}$ EDTA; $3 \mu \mathrm{mol} \mathrm{K} \mathrm{HPO}_{4} ; 0.256 \mu \mathrm{mol} \mathrm{NADH} ; 0.05$ to I $\cdot 0 \mathrm{mg}$ protein of cell-free extracts; final $\mathrm{pH} 7 \cdot 3$, brought to a volume of $2.0 \mathrm{ml}$ with distilled water. Protein was determined by the method of Kunitz (1952).

Pinchot's (1953) method was used to measure ATP formation (coupled oxidative phosphorylation). In addition to the reaction mixture used for the enzymic assay of NADH oxidase the following reagents were used : $4.0 \mu \mathrm{mol}$ AMP; $0.225 \mu \mathrm{mol} \mathrm{ADP}$; $10 \mu \mathrm{mol}$ glucose $0.06 \mathrm{mg}$ bovine serum albumin; I5 units hexokinase (lyophilized, yeast, salt free; Calbiochem); 30 units glucose-6-phosphate dehydrogenase (Torula yeast; Calbiochem); with or without $0.22 \mu \mathrm{mol}$ NADP. In this reaction NADH is oxidized, decreasing extinction at $340 \mathrm{~nm}$. The ATP formed is converted to glucose-6-phosphate by hexokinase and subsequently oxidized by glucose-6-phosphate dehydrogenase with a simultaneous reduction of NADP. NADP reduction is measured as the difference in the rate of extinction decrease at $340 \mathrm{~nm}$ between reactions with and without NADP. Consequently, if the membrane fractions couple the oxidation of one mole of $\mathrm{NADH}$ to the reduction of one mole of NADPH, the slope ( $\mu$ mol NADH oxidized; $E_{340} / \mathrm{min} / \mathrm{mg}$ protein) of the whole reaction is one, thus a P:O ratio of one. If coupling does not occur the reaction with NADP has the same slope as the reaction without NADP, due solely to NADH oxidation (a P:O of zero).

In a separate measurement ATP production due to adenylate kinase activity was subtracted from the total ATP formed, leaving only ATP formed from oxidative phosphorylation. This control was used separately without NADH as substrate, thus permitting observation of the endogenous ATP formed by adenylate kinase.

Concentrated stock solutions of inhibitors and uncouplers were dissolved in ethanol or distilled water and used in 0.2 to $0.05 \mathrm{ml}$ and $2 \mu 1$ portions, respectively. When examining their effect upon the $\mathrm{P}: \mathrm{O}$ ratio of the control the difference was taken as the $\mathrm{P}: \mathrm{O}$ ratio of the whole reaction with effector, and the reaction without NADP with effector.

Spectrophotometric absorption spectra. Difference absorption spectra were obtained from membrane suspensions of bacteria grown aerobically with and without haematin. The growth was thoroughly washed in phosphate buffer (O. $5 \mathrm{M}$ ) to eliminate any excess haematin. Since the bacteria were harvested in exponential phase at a relatively high $\mathrm{pH}$, most of the haematin remained suspended. Bacteria were broken in an X-press and, after centrifuging, the low-speed fraction containing the particulate material was used. Spectra were obtained using a Cary I4 Recording Spectrophotometer employing a cell pathlength of $0 \cdot 2 \mathrm{~cm}$. Air was the oxidant and a few crystals of sodium dithionite the reductant. The reduced-cyanide minus reduced-spectrum was the difference between the dithionite reference and a cuvette with the same dithionite-reduced sample plus a few crystals of $\mathrm{KCN}$. A reduced-carbon monoxide minus reduced-spectrum was the difference between the dithionite-reference and the same dithionite-reduced sample bubbled for a few minutes with $\mathrm{CO}$. 

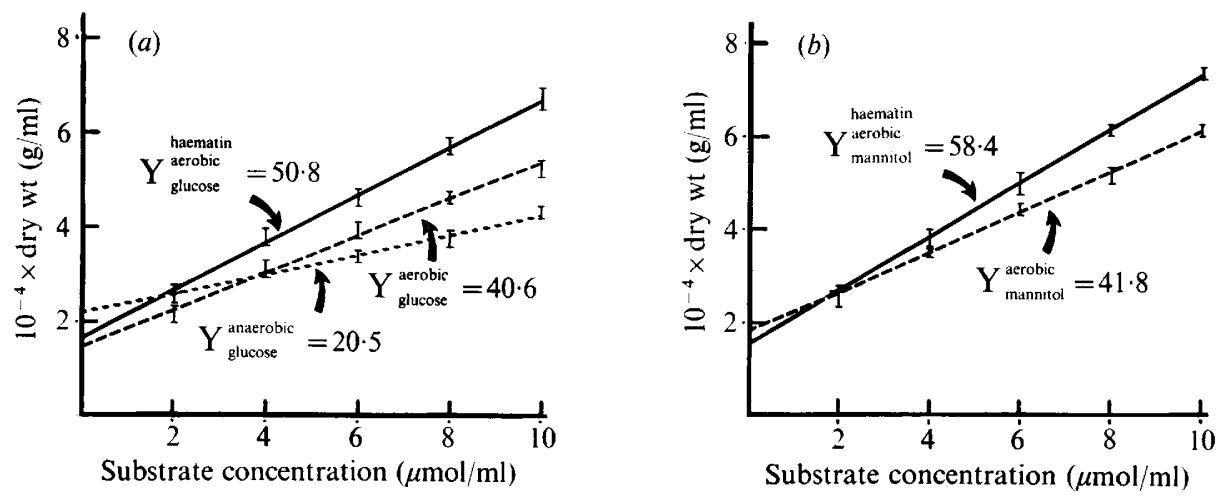

Fig. I. Molar growth yields with (a) glucose and (b) mannitol. See text for methods and discussion.

\section{RESULTS AND DISCUSSION}

A preliminary report (Ritchey, VanWie \& Seeley, I972) presented evidence for the development of a cyanide-sensitive oxidative pathway in hematin-grown Streptococcus faecalis var. zymogenes. Manometric techniques also revealed that resting suspensions of haematin-grown bacteria had an increased rate of oxygen uptake, and that haematin could not be used as a substrate. In this communication, functional cytochrome(s) have been identified and probably account for greater ATP production when there is a source of haematin.

Changes in ATP production were monitored either by molar growth yields or in cell-free extracts as $\mathrm{P}: \mathrm{O}$ ratios in vitro.

End-product analysis of the spent medium from the molar growth yields $(\mathrm{Y})$ on glucose showed that the primary product during aerobic growth was acetate $(92 \%)$, with small amounts of lactate, acetylmethylcarbinol and ethanol. During anaerobic growth lactate was the primary product $(89 \%)$ with small amounts of acetate and only traces of ethanol and acetylmethylcarbinol or 2,3-butanediol. The aerobic $Y_{\text {glucose }}$ of $40 \cdot 6$ (Fig. I $a$ ) can be expected to be the product of slightly less than $4 \mathrm{~mol} \mathrm{ATP} / \mathrm{mol}$ substrate. The anaerobic $\mathrm{Y}_{\text {glucose }}$ of 20.5 should be slightly more than 2 mol ATP. From these data the $Y_{A T P}$ can be considered to be 10.2 (g dry wt/mol ATP). Bauchop \& Elsden (I960) observed an anaerobic $Y_{\text {glucose }}$ of 22 with $S$. faecalis and a $Y_{\mathrm{ATP}}$ of 10.5. Since these organisms closely resemble each other, the molar growth yields seem in close enough agreement to substantiate this method.

Whenever haematin was added to the growth medium the products of aerobic growth were nearly the same, but the $Y_{\text {glucose }}$ was increased to 50.8. Haematin added to the medium of anaerobically grown bacteria changed neither the products nor the $\mathrm{Y}_{\text {glucose }}$. When growth is aerobic on glucose with haematin, $5 \mathrm{~mol}$ ATP are generated per mol substrate as compared with 4 due entirely to substrate level phosphorylation in non-haematin grown cultures.

Smalley et al. (I968) calculated a P:O ratio in the absence of haematin from the difference in the aerobic $Y_{\text {mannitol }}$ and the aerobic $Y_{\text {glucose }}$ to indicate oxidative phosphorylation of 0.6 to 0.7 in $S$. faecalis rocr. Product analysis of mannitol grown $S$. faecalis var. zymogenes indicated production of about $4 \mathrm{~mol} \mathrm{ATP} / \mathrm{mol}$ substrate. Aerobically $Y_{\text {mannitol }}$ was $4 \mathrm{r} \cdot 8$ but with haematin, while the same products were formed, $Y_{\text {mannitol }}$ was 58.4 (Fig. I $b$ and Table I). We present molar growth yields as buttressing evidence for oxidative phosphorylation. Whenever $Y_{\text {mannitol }}$ and $Y_{\text {glucose }}$ were compared in bacteria grown aerobically with haematin, 
Table I. Molar growth yields ( $Y$ ) for S. faecalis var. zymogenes

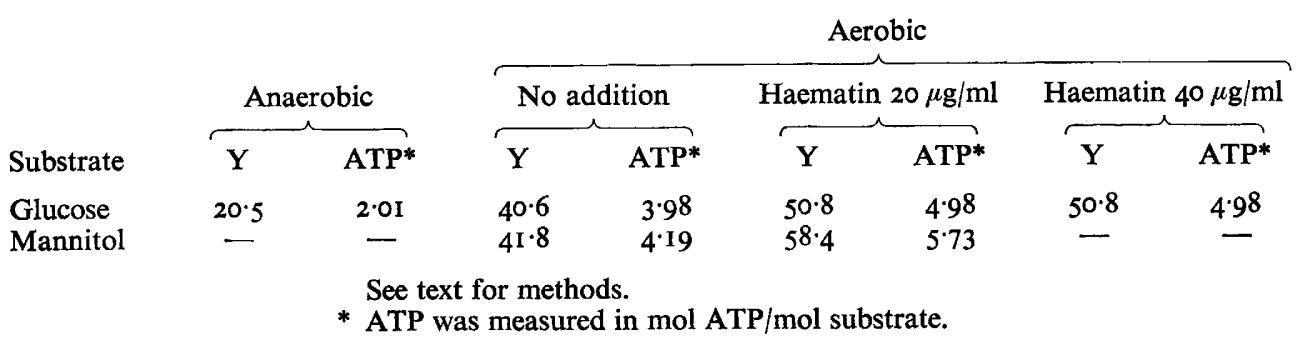

a $\mathrm{P}: \mathrm{O}$ ratio of 0.75 was obtained. Extra ATP production can be realized by the utilization of the extra pair of electrons on mannitol. Evidently the inclusion of haematin in the growth medium, with subsequent cytochrome induction, enables this bacterium to couple the oxidation of NADH to the formation of ATP. Haematin was not used as a substrate to provide energy because the addition of $40 \mu \mathrm{g}$ haematin $/ \mathrm{ml}$, instead of the normal $20 \mu \mathrm{g} / \mathrm{ml}$, did not increase the aerobic $Y_{\text {gluoose }}$; the same $y$-axis intercept indicated that haematin was not used as a source of energy.

In the absence of haematin ATP production from oxidative phosphorylation, as suggested by molar growth yields, did not occur in S. faecalis var. zymogenes. This differs from the findings of Smalley et al. (1968) with $S$. faecalis rocI, but is similar to the findings of Bryan-Jones \& Whittenbury (I969) with $S$. faecalis strain 58 I. In an unpublished survey we have found variation in the mechanism of aerobic ATP generation not only between Streptococcus spp., but also between strains of a given species (e.g. S. faecalis).

Table 2 shows the effect of several inhibitors upon the oxidation of NADH by the highspeed membrane fraction from bacteria grown without haematin. These membranes contained little cytoplasm as the NADH oxidase activity had been purified 25 -fold from the original broken preparation. The concentrations of $\mathrm{NaN}_{3}$ used inhibited the activity in membranes from growth with haematin less than those from growth without haematin. Potassium cyanide blocked NADH oxidation more efficiently in the haematin-induced pathway, implying blockage of a cytochrome system. An inhibitor, 2- $n$-heptyl-4-hydroxyquinoline- $N$-oxide (HOQNO), reported by Jackson \& Lightbown (1956) to be more effective with bacterial preparations than antimycin, displayed discriminatory inhibition of the cytochrome system. Antimycin A also partially inhibited NADH oxidation in this system, supporting the evidence of a Site II level of oxidative phosphorylation. Very low concentrations of both rotenone and amytal showed inhibition at the Site I level of a cytochrome respiratory chain.

Whenever haematin was incorporated in the growth medium, cell-free extracts of purified membranes exhibited an NADH oxidation which was sensitive to many inhibitors of a classical cytochrome-mediated electron transport system. Extracts from cultures grown without haematin were less sensitive to the inhibitors rotenone, amytal, HOQNO, antimycin $\mathrm{A}$, and $\mathrm{KCN}$. The NADH oxidation system under these conditions is flavin in nature and is only sensitive to high concentrations of these inhibitors (Faust \& VanDemark, 1970). Our results concur with those of Bryan-Jones \& Whittenbury (I969), since antimycin A and KCN were found to be potent inhibitors $\left(\mathrm{NaN}_{3}\right.$ was a weaker inhibitor) of $\mathrm{NADH}$ oxidation in membrane preparations from haematin-grown bacteria. The reason that the haematininduced pathway is less sensitive to $\mathrm{NaN}_{3}$ could be due to the nature of the haem group as it appears in the apoenzyme of the cytochrome. Since $\mathrm{NaN}_{3}$ will bind thioester bonds, 
Table 2. Effect of inhibitors on NADH oxidation and oxidative phosphorylation

Fractions were prepared and tested as described in Methods.

\begin{tabular}{|c|c|c|c|}
\hline \multirow[b]{2}{*}{ Inhibitor } & \multirow[b]{2}{*}{$\begin{array}{r}\text { Concn } \\
(\mathrm{mM})\end{array}$} & \multicolumn{2}{|c|}{ Inhibition of NADH oxidation* (\%) } \\
\hline & & $\begin{array}{l}\text { Haematin-grown } \\
\text { membranes }\end{array}$ & $\begin{array}{l}\text { Non-haematin grown } \\
\text { membranes }\end{array}$ \\
\hline \multirow[t]{2}{*}{$\mathrm{NaN}_{3}$} & $10 \cdot 0$ & 20 & 38 \\
\hline & $50 \cdot 0$ & 62 & 100 \\
\hline \multirow[t]{2}{*}{$\mathrm{KCN}$} & 0.6 & 43 & 12 \\
\hline & $1 \cdot 0$ & 100 & 20 \\
\hline HOQNO & $0 \cdot I^{\prime}$ & 72 & 15 \\
\hline Antimycin A & 0.008 & 44 & 6 \\
\hline Amytal & 0.01 & 15 & 4 \\
\hline Rotenone & 0.04 & $2 \mathrm{I}$ & 7 \\
\hline \multirow[t]{3}{*}{ Batho. S. } & $0 \cdot 1$ & 12 & N.D. \\
\hline & & \multicolumn{2}{|c|}{ Uncoupling of oxidative phosphorylation } \\
\hline & $\begin{array}{l}\text { Concn } \\
\text { (mM) }\end{array}$ & $\begin{array}{l}\text { Haematin-grown } \\
\text { membranes } \\
\mathrm{P}: \mathrm{O}\end{array}$ & $\begin{array}{c}\text { Non-haematin-grown } \\
\text { membranes } \\
\text { P:O }\end{array}$ \\
\hline Complete & o & 0.28 & 0.00 \\
\hline $\mathrm{KCN}$ & 0.6 & 0.30 & N.D. \\
\hline Antimycin A & 0.008 & 0.08 & N.D. \\
\hline HOQNO & $0 \cdot \mathrm{I}$ & 0.00 & N.D. \\
\hline
\end{tabular}

N.D., not tested; HOQNO, 2-n-heptyl-4-hydroxyquinoline- $N$-oxide; and Batho. S., bathophenanthroline disulphonate.

* The absolute rate of NADH oxidation corresponds to $0 \%$ inhibition.

one could expect to see greater inhibition of a flavin oxidase system where the riboflavin moiety is bound to the apo-enzyme by a thioester bond.

No ATP generation from NADH oxidation was found with non-haematin extracts when up to I.O $\mathrm{mg}$ (protein) of the high-speed fraction or the cytoplasm was used. The high-speed fraction $(0.05 \mathrm{mg}$ protein) from haematin-grown cells coupled the oxidation of NADH to the formation of ATP (Table 2). In several experiments $\mathrm{P}: \mathrm{O}$ ratios from 0.14 to 0.36 were found, depending upon the speed and temperature of the isolation. The ATP formed by adenylate kinase was subtracted from the ATP formed in the whole reaction and was never more than $10 \%$. Adenylate kinase activity was inhibited by AMP, EDTA, and KF and was partially eliminated by washing the high-speed fraction. Antimycin A and HOQNO gave $44 \%$ and $72 \%$ inhibition of NADH oxidation and uncoupled the ATP formation (Table 2). Significant results were obtained with bathophenanthroline disulphonate, since this compound decreased the $\mathrm{P}: \mathrm{O}$ ratio by $85 \%$, but inhibited the NADH oxidation by only $12 \%$. $\mathrm{KCN}$ did not decrease the $\mathrm{P}: \mathrm{O}$ ratio, but inhibited the NADH oxidation by $43 \%$.

The uncoupler, bathophenanthroline disulfonate, supports the present evidence that ATP production can be separated from the electron-respiratory chain without inhibition of electron transport. Similarly, when KCN was used only the rate of electron transport was affected, not ATP production. Such findings can be attributed to the purity of the highspeed fraction of membranes and the successful inhibition of the adenylate kinase. The data suggest inhibition of the rate of electron transport in a cytochrome system, which can be independent of any ATP formation, and also suggest uncoupling of phosphorylation resulting from cytochrome-mediated electron flow. 
Table 3. Sites of NADH oxidase in S. faecalis var. zymogenes

Fractions were prepared as described in the text.

\begin{tabular}{|c|c|c|c|c|c|c|c|}
\hline & & & Extra & & & & \\
\hline & $\begin{array}{l}\text { Lor } \\
\text { mer }\end{array}$ & & $\begin{array}{l}\text { Hig } \\
\text { men }\end{array}$ & & Cyt & & Total \\
\hline & $\mathrm{TU} \dagger$ & SA & TU† & SA $\ddagger$ & TU† & SA $\uparrow$ & (TU) \\
\hline Haematin-grown & 369 & $22 \cdot 0$ & 394 & $36 \cdot 0$ & 182 & $I \cdot 7$ & 945 \\
\hline Non-haematin-grown & $26 \cdot 0$ & $I \cdot 6$ & $31 \cdot 0$ & $3 \cdot 3$ & 340 & $2 \cdot 5$ & 397 \\
\hline & $\begin{array}{l}* \text { Tota } \\
\dagger \text { Tota } \\
+ \text { SA }=\end{array}$ & $\begin{array}{l}\text { acts } \\
s= \\
\text { cific }\end{array}$ & $\begin{array}{l}\text { g we } \\
\Delta E_{340} \\
\text { (unit }\end{array}$ & $\begin{array}{l}\text { acter } \\
\text { O. I } n \\
\text { prote }\end{array}$ & & & \\
\hline
\end{tabular}

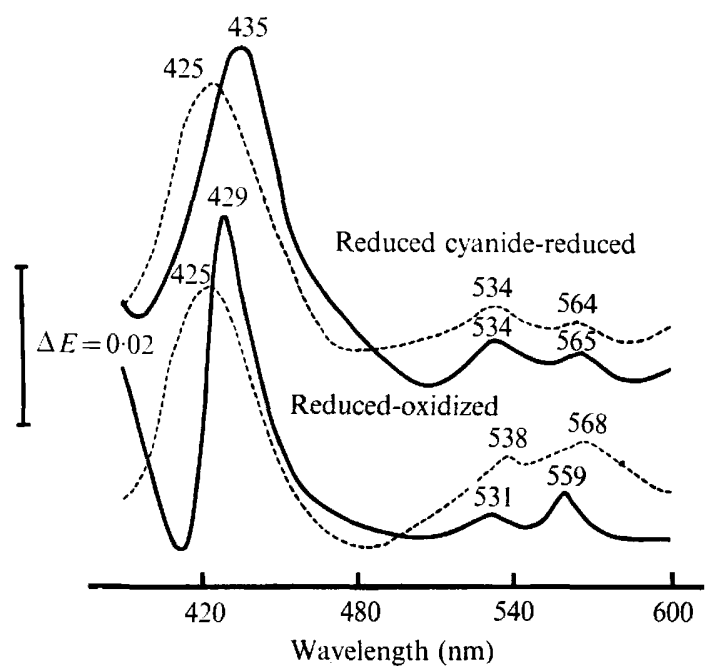

Fig. 2. Reduced-oxidized and reduced cyanide-reduced spectra of $S$. faecalis var. zymogenes grown in the presence of haematin and a haematin control. See text for preparation and results. - . - , Haematin control; - , haematin-grown membranes.

The sites of NADH oxidation were explored (Table 3). Cultures grown with haematin: (I) have more than twice the total NADH oxidizing power of non-haematin-grown cultures; and (2) have the site of NADH oxidation primarily in the membranes, thus agreeing with the findings of Bryan-Jones \& Whittenbury (1969). The high-speed fractions from haematingrown cultures had a deep brown colour with a red tint, while those from non-haematingrown cultures were white with a yellow tint. Thus another outstanding difference between the haematin-induced and the flavin pathways is that bacteria grown with haematin have a membrane-bound NADH oxidase system, while those grown without haematin have a soluble NADH oxidase. The usual bacterial cytochrome systems are obligately membranebound. Henderson (197I) reported that there has been only one preliminary description of a 'soluble' system which was capable of oxidative phosphorylation. Thus, knowledge of the location of the NADH oxidase system can contribute to the identification of a cytochrome system.

Spectral data support the theory of cytochrome induction (Fig. 2). A notable difference is 
seen between the peaks of the haematin $(568,538$ and $425 \mathrm{~nm})$ and those of the membrane preparation of haematin-grown cells $(559,53 \mathrm{I}$ and $429 \mathrm{~nm})$. When properly washed, little or no absorption was seen at $425 \mathrm{~nm}$ in cells to which haematin was added after growth. Membranes of anaerobically grown bacteria never exhibited spectra around 425 to $430 \mathrm{~nm}$. The effect of KCN upon the reduced spectra of the same membrane suspensions (aerobically haematin-grown) is shown in the upper curves of Fig. 2. In the reduced-cyanide minus reduced-spectrum a marked difference is evident between the absorption maximum of the haematin control at $425 \mathrm{~nm}$ and that at $435 \mathrm{~nm}$ for the membranes of cells grown with haematin. When NADH (I $\mu \mathrm{mol} \mathrm{NADH}$ or lactic acid plus lactate dehydrogenase) was used to obtain a reduced- minus oxidized-spectrum with HOQNO preventing reoxidation the results were almost identical with those in the lower portion of Fig. 2; however, the intensity of the absorption was less. The advantage of this procedure was that the haematin control was not reduced. In contrast, when NADH reduced the preparation in the presence of $\mathrm{KCN}$, the same shift in the soret region was seen as that appearing in the upper left of Fig. 2. If neither HOQNO nor KCN were used, only slight reduction could be seen due to the reoxidation of the cytochrome system. In the reduced-carbon monoxide minus reducedspectrum a cytochrome of the $b$ type (559) did not appear. A cytochrome of the $a$ type did appear in the lower soret region and was significantly different than the haematin control.

The spectral data revealed a membrane-bound cytochrome of the $b$ type which may be the same as that found by Bryan-Jones \& Whittenbury (I969) since both had peak at $559 \mathrm{~nm}$. The exact identity of the cytochrome oxidase reported in this communication has not been determined.

The data presented lead to the conclusion that the membranes of haematin-grown cells contained: (I) the components giving cytochrome spectra; (2) the major portion of the $\mathrm{NADH}$ oxidase; and (3) the mechanism for cell-free oxidative phosphorylation. Molar growth yields gave evidence for oxidative phosphorylation in growing cultures which contained haematin, thus evidence for a functional cytochrome system. When bacteria were grown without haematin: (I) a soluble flavin system developed, and (2) oxidative phosphorylation did not occur.

\section{REFERENCES}

BAUChOP, T. \& ElsDen, S. R. (1960). The growth of microorganisms in relation to their energy supply. Journal of General Microbiology 223, 457-469.

BRYAN-JoNeS, D. G. \& WhitTenBURY, R. (1969). Haematin-dependent oxidative phosphorylation in Streptococcus faecalis. Journal of General Microbiology 583, 247-260.

Faust, P. J. \& VanDemark, P. J. (1970). Phosphorylation coupled to NADH oxidation with fumarate in Streptococcus faecalis IOCI. Archives of Biochemistry and Biophysics 137, 392-398.

Galuin, J. I. \& VANDemark, P. J. (1964). Evidence for oxidative phosphorylation in Streptococcus faecalis. Biochemical and Biophysical Research Communications 17, 630-635.

HeNDERson, P. J. F. (1971). Ion transport by energy-conserving biological membranes. Annual Review of Microbiology 25, 393-428.

HoreCKer, B. L. \& Kornberg, A. (1948). The extinction coefficients of the reduced band of pyridine nucleotides. Journal of Biological Chemistry 175, 385-394.

JACKson, F. L. \& LightBown, J. W. (1956). Induction of dihydrocozymase oxidase activity of pig-heart muscle and bacterial preparations by 2-heptyl-4-hydroxyquinoline- $N$-oxide. Biochemical Journal $\mathbf{6 3}$, I6P.

KunITZ, M. (1952). A method of protein determination using trichloracetic acid. Journal of General Physio$\log y 35,423-428$.

O'KANe, D. J. \& Gunsalus, I. C. (1948). Pyruvic acid metabolism. A factor required for oxidation by Streptococcus faecalis. Journal of Bacteriology 56, 449-506. 
Pinchot, G. B. (1953). Phosphorylation coupled to electron transport in cell-free extracts of Alcaligenes faecalis. Journal of Biological Chemistry 205, 65-82.

Ritchey, T. W., VANWIE, J. \& Seeley, H. W. JUn. (1972). A cyanide-sensitive respiratory pathway of streptococci grown with haematin. Abstract of the Annual Meeting of the American Society for Microbiology, 158.

SiJPESTEIJN, A. K. (1970). Induction of cytochrome formation and stimulation of oxidative dissimilation by haemin in Streptococcus lactis and Leuconostoc mesenteroides. Antonie van Leeuwenhoek, 36, 335-348.

Smalley, A. J., Jahrling, P. \& VANDemark, P. J. (I968). Molar growth yields as evidence for oxidative phosphorylation in Streptococcus faecalis strain IOCI. Journal of Bacteriology 96, I595-I600.

VAN DER WIEL-KoRstANJE, J. A. A. \& DE VRIES, W. (1973). Cytochrome synthesis by Bifidobacterium during growth in media supplemented with blood. Journal of General Microbiology 75, 4I 7-4I9.

WhitTenBury, R. (1964). Hydrogen peroxide formation and catalase activity in the lactic acid bacteria. Journal of General Microbiology 35, 13-26. 